\title{
Measurement of resistance force of conveyor belt passing on carrier roller (Development of substitutive method with self-traveling roller)
}

\author{
Kanata MIYAZAKI, Kazuya Okubo, Kiyotaka Obunai \\ Doshisha graduate school, Kyotanabe city tataramiayakodani 1-3, Kyoto, 610-0394, Japan \\ Doshisha University, Kyotanabe city tataramiayakodani 1-3, Kyoto, 610-0394, Japan
}

\begin{abstract}
The purpose of this study is to reveal specific factors which determined the experimental results obtained by selftraveling roller for evaluating the property of indentation rolling resistance, comparing the data shown by conventional test system. In the novel test method with selftraveling roller, the cart which was the loading part of a carrier roller was dragged in the driving direction vertically pushing the flat conveyor belt between the roller and rigid and straight aluminum rail flame. In conventional test method with endless driven belt, Indentation load and indentation rolling resistance was measured by two load cells attached between bearing holder for carrier roller and the flame vertically and horizontally, respectively.

The trace of indentation displacements were not symmetric, where time to recovery was longer than that to indent. The relationship between their experimental results obtained by the novel method in which self-traveling roller was applied was well agreed with that by conventional test method. Hysteresis loops were observed, when loaddisplacement curves was investigated under simple vertical indentation. The hysteresis loss energy was not depended on the clamping condition, while the increasing point of the curves was different. Novel test method with self-traveling roller had a potential as a substitutive test method to evaluate the indentation rolling resistance of the conveyer belt.
\end{abstract}

Keywords: Method with self-traveling roller method, Indentation rolling resistance, Belt conveyor, Hysteresis loss.

\section{Introduction}

Belt conveyors are, in most cases, the most cost-effective solution for handling bulk material mass flows over short and medium conveying distances ${ }^{(1)}$. Due to their numerous advantages, belt conveyors are also used in other industries, such as in natural resource processing, smelting, cement and lime production, pulp and paper production, sea and river ports, civil engineering, agriculture, sugar factories, power plants and others ${ }^{(2)}$. Resistance force of conveyor belt passing on carrier roller is called indentation rolling resistance, which is one of the most important factors to design belt conveyor system. To measure the indentation rolling resistance, the endless belt should be conventionally driven on driving and driven two pulleys with one carrier roller at least. This is most popular and simple method. On the other hand, a novel method has been proposed to evaluate the rolling resistance in which one carrier roller is traveled on the flat conveyor belt. In the novel test method with the self-traveling roller, easy measurements are expected in laboratory scale, because an opened conveyor belt cut properly to short length is applied to the experiment instead of endless belt. Considering application of the novel method to industry, the data obtained by the method must be corresponded reasonably to one obtained by conventional method. However, specific factors which determined the experimental results have not been discussed for the proposed novel method, comparing the data by conventional test method.

The purpose of this study is to reveal specific factors which determined the experimental results obtained by selftraveling roller for evaluating the property of indentation rolling resistance, comparing the data shown by conventional test system..

\section{Theory}

Fig.1 shows a schematic figure of the distributed contact force between idler roller and conveyor belt. Pressures by the indentation $\mathrm{P}_{1}, \mathrm{P}_{2}$ are applied to conveyor belt when a conveyor belt travels on idler roller. The $\mathrm{P}_{1}, \mathrm{P}_{2}$ are defined as equation (1) and (2). 
pressure, contact angle (forwarding part), contact angle (following part) respectively. Fig.2 shows an illustration of detail of contact area.

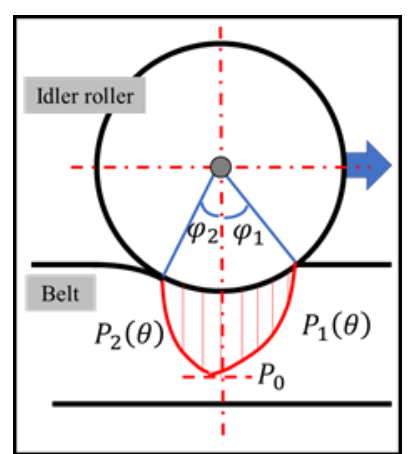

Fig.1 Schematic of indentation.

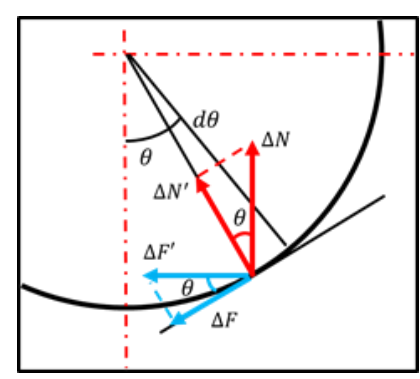

Fig.2 Microscopic schematic of contact area.

Reaction force of vertical direction $\Delta N$ is

$$
\Delta N(\theta)=P_{0} R b \cos \left(\frac{\pi}{2 \varphi} \theta\right) d \theta
$$

where, $R$ and $b$ denote diameter of carrier roller and width of conveyor belt respectively. Normal force $\Delta N^{\prime}$ is

$$
\Delta N^{\prime}(\theta)=P_{0} R b \cos \theta \cos \left(\frac{\pi}{2 \varphi} \theta\right) d \theta
$$

Resistance force of tangent direction $\Delta F$ is

$$
\Delta F(\theta)=P_{0} R b \cos \theta \cos \left(\frac{\pi}{2 \varphi} \theta\right) d \theta
$$

Dragging component of the tangential resistance force $\Delta F^{\prime}$ is

$$
\Delta F^{\prime}(\theta)=\mu P_{0} R b \cos ^{2} \theta \cos \left(\frac{\pi}{2 \varphi} \theta\right) d \theta
$$

Total resistance force $\mathrm{F}$ in traveling direction is calculated as,

$$
\begin{aligned}
F= & \int_{0}^{+\varphi_{1}} \mu b R P_{0} \cos ^{2} \theta \cos \left(a_{1} \theta\right) d \theta \\
& \quad+\int_{-\varphi_{2}}^{\theta} \mu b R P_{0} \cos ^{2} \theta \cos \left(a_{2} \theta\right) d \theta \\
= & \frac{\mu}{2 \pi}\left(\varphi_{1}-\varphi_{2}\right) b R P_{o}
\end{aligned}
$$

Taking $\mathrm{W}$ for indentation load, $P_{0}$ is

$$
\begin{array}{r}
P_{1}=P_{0} \cos \left(\frac{\pi}{2 \varphi_{1}} \theta\right) \\
P_{2}=P_{0} \cos \left(\frac{\pi}{2 \varphi_{2}} \theta\right) \\
P_{0}=\frac{\pi}{2\left(\varphi_{1}+\varphi_{2}\right) b R} W
\end{array}
$$

At last, Indentation rolling resistance $\mathrm{F}$ is

$$
F=\frac{\mu}{2}\left(\frac{\varphi_{1}-\varphi_{2}}{\varphi_{1}+\varphi_{2}}\right) W
$$

It is shown that indentation rolling resistance is proportional to indentation load and depending on the degree of asymmetry of contact angle.

\section{Test method}

\subsection{Novel test method with self-traveling roller}

Fig.3 shows the illustration of the novel test method with self-traveling roller. Commercially available rubber conveyer belt (width $=150 \mathrm{~mm}$ ), was used as the specimen. Table 1 shows some dimensions of the test machine. The cart which was the loading part of a carrier roller was dragged in the driving direction vertically pushing the flat conveyor belt between the roller and rigid and straight aluminum rail flame set under the belt. The rotational bearing holder for the shaft of roller was set under a linear motion bearing to be free for the motion in driving direction. Indentation load was measured by load cells set vertically with the linear motion bearing, while the indentation rolling resistance was also measured by a load cell horizontally set between the bearing unit and rigid part of driven cart.

Dragging velocity was obtained by equation below,

$$
\mathrm{V}=s / t
$$

where, $s$ and $t$ denote interval length of the bolts set on the side of aluminum rail and interval time of pulse waves synchronized with location of bolts obtained by proximity sensor, respectively.

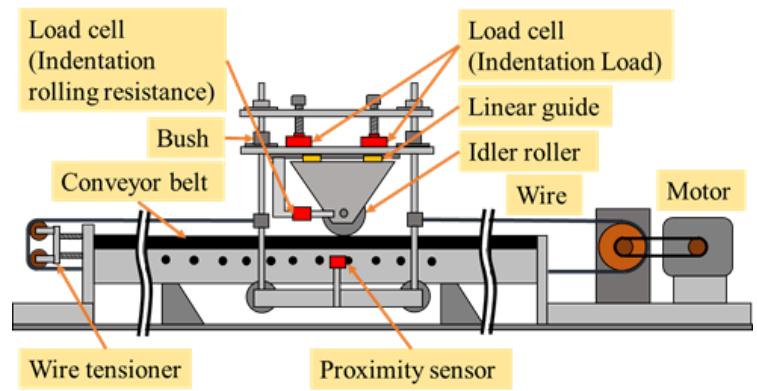

Fig.3 Schematic of test method with self traveling roller. 
Table 1 Detail of self traveling type test machine

\begin{tabular}{|c|c|}
\hline Total length & 5500 \\
\hline Carrier roller width $[\mathrm{mm}]$ & 180 \\
\hline Carrier roller diameter $[\mathrm{mm}]$ & 89.1 \\
\hline
\end{tabular}

Displacements of two points marked on the side surface of the belt in white color were also measured by high speed camera (Fig.4).

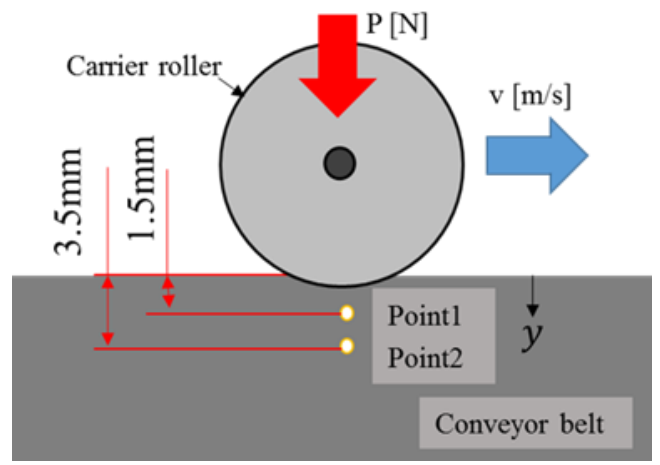

Fig.4 Side view of belt.

\subsection{Conventional test method with endless driven belt}

Fig.5 shows a conventional test method with endless driven belt on two pulleys. Table 2 shows the dimensions of the conventional test machine. Indentation load and indentation rolling resistance was measured by two load cells attached between bearing holder for carrier roller and the flame vertically and horizontally, respectively.

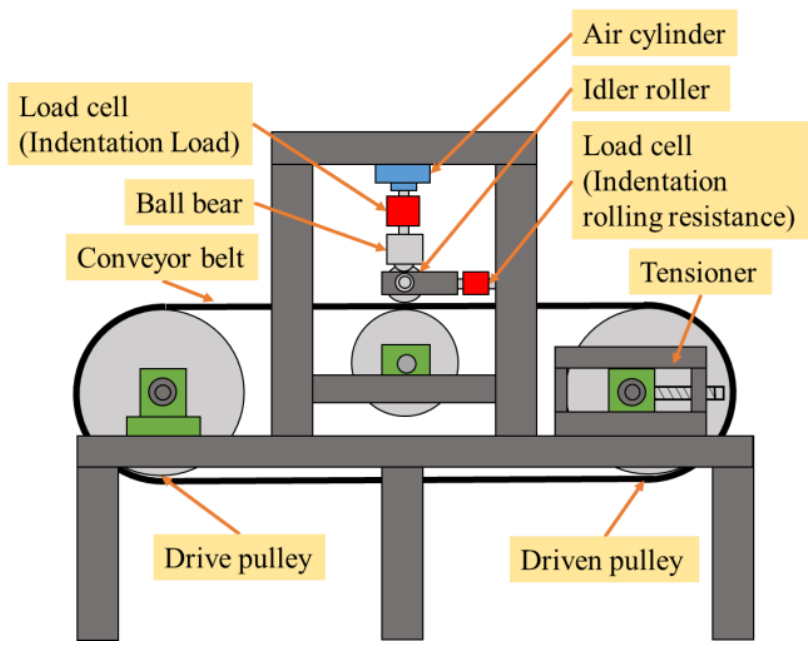

Fig.5 Conventional test method.
Table2 Detail of circulated type test machine

\begin{tabular}{|c|l|}
\hline Total length [mm] & 2800 \\
\hline Carrier roller diameter [mm] & 89.1 \\
\hline Carrier roller width [mm] & 600 \\
\hline Drive pulley diameter[mm] & 800 \\
\hline Drive pulley width[mm] & 900 \\
\hline Driven pulley diameter[mm] & 800 \\
\hline Driven pulley width $[\mathrm{mm}]$ & 900 \\
\hline Bottom roller diameter[mm] & 400 \\
\hline Bottom roller width $[\mathrm{mm}]$ & 600 \\
\hline
\end{tabular}

\section{Result and discussion}

\subsection{Indentation displacement}

Fig. 6 shows example data of the trace of point 1 and point 2 describing indentation displacement of conveyor belt measured by the novel test method with self-traveling roller. The trace of indentation displacements were not symmetric, where time to recovery was longer than that to indent.

Fig.7 shows the relationship between maximum indentation displacement and indentation load. Indentation displacement was almost linear to the indentation load in the range of the indentation load in the tests.

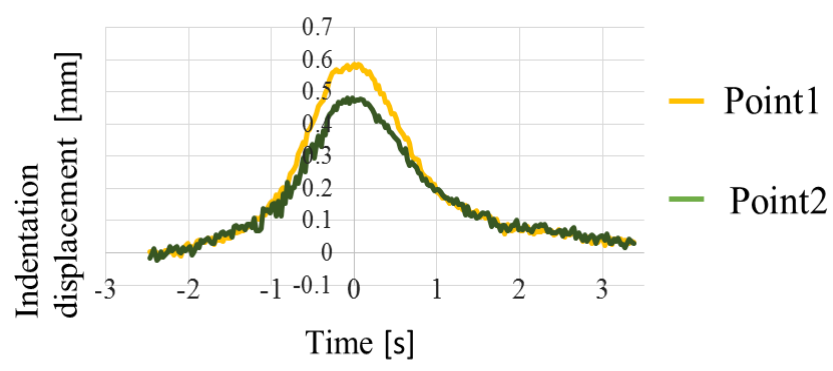

Fig.6 Trace of indentation displacement.

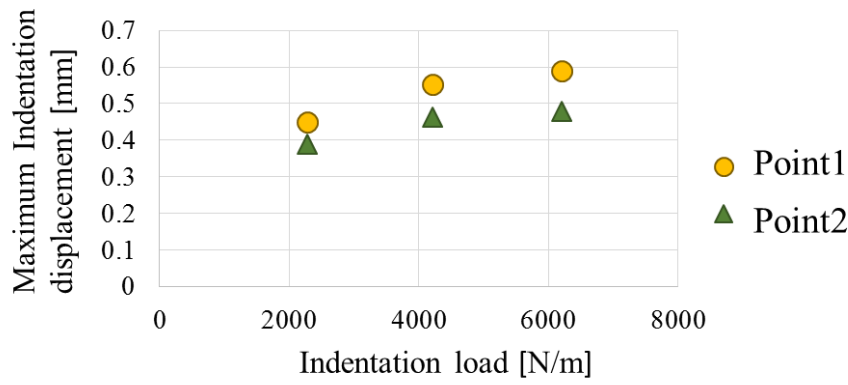

Fig.7 Maximum indentation displacement. 


\subsection{Indentation rolling resistance}

Fig. 8 shows the indentation rolling resistance with respect to the indentation load. The relationship between their experimental results obtained by the novel method in which self-traveling roller was applied was well agreed with that by conventional test method. Fig.9 shows the comparison of clamping conditions of conveyor belts for each method. To clear the influence of the clamping condition on the test data, difference of load-displacement curves was investigated under simple vertical indentation on each testing method.

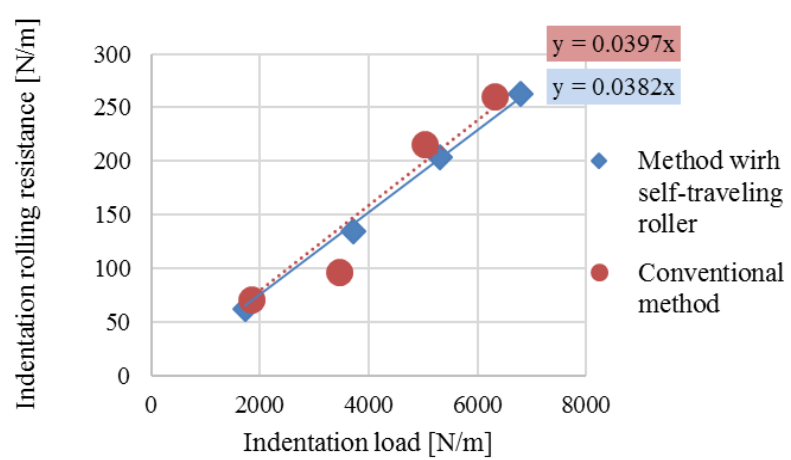

Fig.8 Indentation rolling resistance.
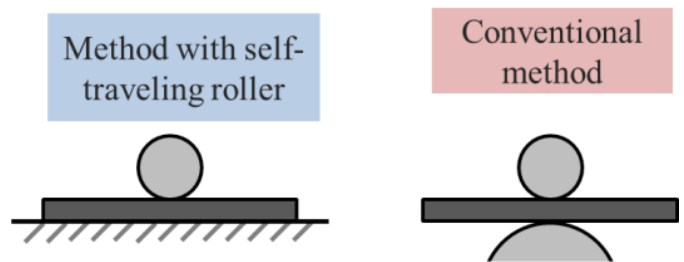

Fig.9 Comparison of clamping conditions of belts.

Fig. 10 shows the typical relations of load-displacement curves. Hysteresis loops were observed in each condition, Fig.11 shows the comparison of experimental data in hysteresis loss energy per unit belt width at the indentation. The hysteresis loss energy was not depended on the clamping condition, while the increasing point of the curves was different. This paper found that basic behavior due to the viscoelastic properties at indentation of the roller to conveyer belt was not affected by the indenting condition of the roller.

It should be said that, when novel method with selftraveling roller was applied, same tendency was obtained in evaluating the indentation rolling resistance force with that by conventional test method using practical endless belt driven on two pulleys. This paper concluded that novel test method with self-traveling roller had a potential as a substitutive test method to evaluate the indentation rolling resistance of the conveyer belt even when size and dimensions were so huge in practical case.

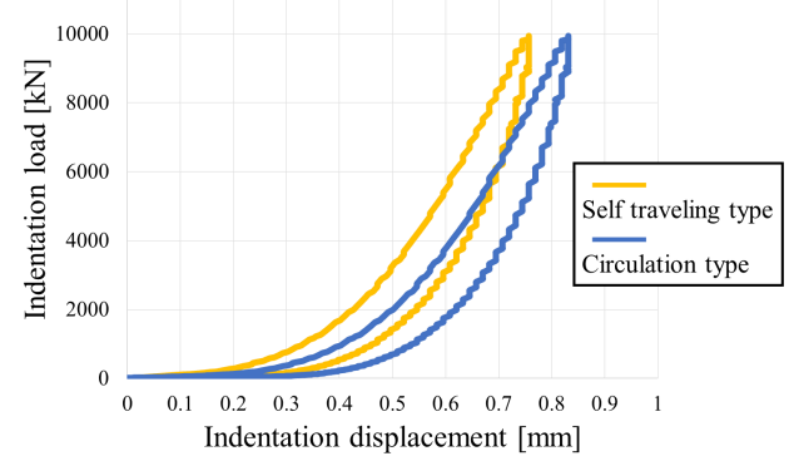

Fig.10 Hysteresis loop.

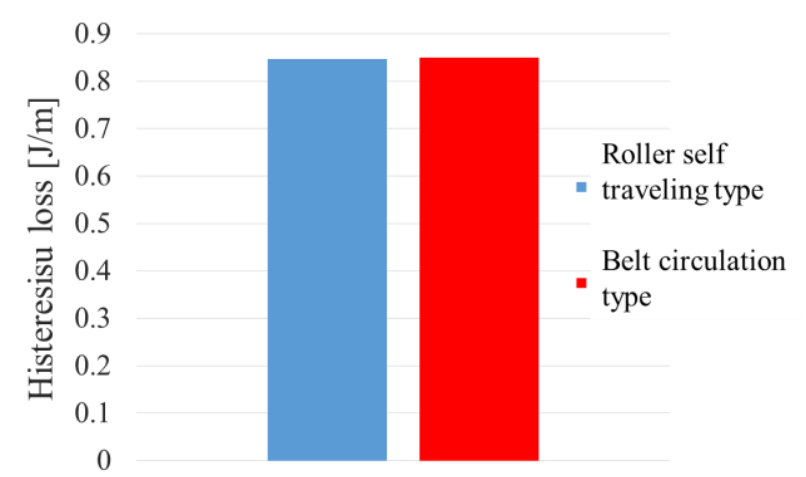

Fig.11 Hysteresis loss.

\section{Conclusions}

(1) The trace of indentation displacements by a circular roller of rubber conveyer belt were not symmetric, where time to recovery was longer than that to indent.

(2) The relationship between their experimental results obtained by the novel method in which self-traveling roller was applied was well agreed with that by conventional test method.

(3) Hysteresis loops were observed, when load-displacement curves was investigated under simple vertical indentation.

(4) The hysteresis loss energy was not depended on the clamping condition, while the increasing point of the curves was different.

(5) Novel test method with self-traveling roller had a potential as a substitutive test method to evaluate the indentation rolling resistance of the conveyer belt. 


\section{References}

(1) You-fu Hou,Quing-rui Meng,"Dynamic characteristics of conveyor belts",Journal of China University of Mining and Technology,Vol.18,issue4,(2008),pp.629633

(2) Dariusz Mazurkiewicz,"Analysis of the ageing impact on the strength of the adhesive sealed joints of conveyor belts", Journal of Materials Processing Technology,Vol.208,Issues.1-3,(2008),pp.477-485 